\title{
Editorial for Special Issue “Optical Remote Sensing of Boreal Forests"
}

\author{
Miina Rautiainen ${ }^{1,2, *,+}$ and Jan Pisek ${ }^{3,+}+\mathbb{C}$ \\ 1 Department of Built Environment, School of Engineering, Aalto University, P.O. Box 14100, \\ FI-00076 Aalto, Finland \\ 2 Department of Electronics and Nanoengineering, School of Electrical Engineering, Aalto University, \\ P.O. Box 15500, FI-00076 Aalto, Finland \\ 3 Tartu Observatory, University of Tartu, Observatooriumi 1, Tõravere, 61602 Tartumaa, Estonia; \\ janpisek@gmail.com \\ * Correspondence: miina.a.rautiainen@aalto.fi; Tel.: +358-504010780 \\ $\dagger$ Joint first authorship.
}

Received: 1 November 2018; Accepted: 7 November 2018; Published: 8 November 2018

Boreal forests (or taiga) are the world's largest terrestrial biome and represent one third of the world's forest cover. Warming in the boreal and neighboring Arctic region is projected to be substantially above the global average, a trend consistent with both model projections and observations. The spatial distribution, structure and composition of vegetation in the boreal zone are expected to undergo significant changes during the coming decades due to climate change. On the other hand, vegetation in the boreal zone will also impact the global climate through its role in carbon cycles and global radiation balance.

This special issue presents a select, compact set of papers covering a wide range of different spatial, spectral, and temporal scales of remote sensing instruments that use different methodologies, but which illustrate the many ways remote sensing data are being used in the boreal region.

Four articles focus on in situ measurements conducted in boreal forests. Mõttus et al. [1] present the daily cycle of Scots pine needle and canopy PRI in a southern boreal forest zone in Europe in the presence of direct solar radiation during the peak growing season of two consecutive years. Kobayashi et al. [2], in turn, introduce the first in situ continuous measurements of canopy scale (overstory + understory) and understory spectral reflectance and vegetation index in an open boreal forest in interior Alaska. Kuusk et al. [3] offer the most comprehensive comparison of different instruments and methods for estimating the gap fraction of (hemi-)boreal canopies to date. Oveland et al. [4] compare both the accuracy and efficiency of three different ground-based laser scanning methods (terrestrial laser scanner, handheld laser scanner and a backpack laser scanner) for tree stem detection in southeastern Norway.

As a bridging study between in situ and satellite observations, Loranty et al. [5] combine field observations of larch forest cover across a $25 \mathrm{~km}^{2}$ upland landscape in northeastern Siberia with high-resolution PlanetScope CubeSat and Landsat satellite observations to determine how the normalized difference vegetation index (NDVI) and the enhanced vegetation index (EVI) are related to forest cover.

Two papers proceed with using remote sensing data to monitor extensive areas in the boreal zone. Regarding fire in the boreal region, Boonprong et al. [6] present a random forest variable importance (RF-VIMP) scheme called multilevel RF-VIMP to compare and assess the relationship between 36 spectral indices (parameters) derived from Landsat data of burnt boreal forest recovery from a single wildfire covering about $10,000 \mathrm{~km}^{2}$ in the Great Xing'an area, China. García-Lázaro [7] follow with the burned area (BA) mapped with a Bayesian classifier in the northeastern Siberian boreal forest from 1982 to 2015 and explore the trends of fire activity in this area. 
Wang and Fensholt [8] conclude the special issue with an analysis of the spatio-temporal patterns of observed converging/diverging trends in vegetation phenology and biomass over recent decades (1982-2013) as a function of major biomes covering the northern hemisphere and encompassing the whole boreal forest area by using GIMMS3g NDVI dataset from AVHRR data and MODIS land cover information.

The articles published in this special issue cover all regions of the boreal zone, including results from areas in Siberia and boreal China which are not commonly reported in international journals. This special issue clearly illustrates the great potential of remote sensing to track the status of boreal forests at multiple scales, while also highlighting a number of remaining challenges.

Author Contributions: M.R. and J.P. jointly wrote this editorial.

Funding: This research received no external funding.

Acknowledgments: We would like to thank the authors who contributed to this Special Issue and to the reviewers who dedicated their time for providing the authors with valuable and constructive recommendations. M.R. was supported by the Academy of Finland (grant: 13286390) and the European Research Council (ERC) under the European Union's Horizon 2020 research and innovation programme (grant agreement No. 771049). J.P. was supported by the Estonian Research Council grant PUT1355 and Mobilitas Pluss MOBERC-11.

Conflicts of Interest: The authors declare no conflict of interest.

\section{References}

1. Mõttus, M.; Hernández-Clemente, R.; Perheentupa, V.; Markiet, V.; Aalto, J.; Bäck, J.; Nichol, C.J. Measurement of Diurnal Variation in Needle PRI and Shoot Photosynthesis in a Boreal Forest. Remote Sens. 2018, 10, 1019. [CrossRef]

2. Kobayashi, H.; Nagai, S.; Kim, Y.; Yang, W.; Ikeda, K.; Ikawa, H.; Nagano, H.; Suzuki, R. In Situ Observations Reveal How Spectral Reflectance Responds to Growing Season Phenology of an Open Evergreen Forest in Alaska. Remote Sens. 2018, 10, 1071. [CrossRef]

3. Kuusk, A.; Pisek, J.; Lang, M.; Märdla, S. Estimation of Gap Fraction and Foliage Clumping in Forest Canopies. Remote Sens. 2018, 10, 1153. [CrossRef]

4. Oveland, I.; Hauglin, M.; Giannetti, F.; Schipper Kjørsvik, N.; Gobakken, T. Comparing Three Different Ground Based Laser Scanning Methods for Tree Stem Detection. Remote Sens. 2018, 10, 538. [CrossRef]

5. Loranty, M.M.; Davydov, S.P.; Kropp, H.; Alexander, D.; Mack, M.C.; Natali, S.M.; Zimov, N.S. Vegetation Indices Do Not Capture Forest Cover Variation in Upland Siberian Larch Forests. Remote Sens. 2018, 10, 1686. [CrossRef]

6. Boonprong, S.; Cao, C.; Chen, W.; Bao, S. Random Forest Variable Importance Spectral Indices Scheme for Burnt Forest Recovery Monitoring-Multilevel RF-VIMP. Remote Sens. 2018, 10, 807. [CrossRef]

7. García-Lázaro, J.R.; Moreno-Ruiz, J.A.; Riaño, D.; Arbelo, M. Estimation of Burned Area in the Northeastern Siberian Boreal Forest from a Long-Term Data Record (LTDR) 1982-2015 Time Series. Remote Sens. 2018, 10, 940. [CrossRef]

8. Wang, L.; Fensholt, R. Temporal Changes in Coupled Vegetation Phenology and Productivity are Biome-Specific in the Northern Hemisphere. Remote Sens. 2017, 9, 1277. [CrossRef]

(C) 2018 by the authors. Licensee MDPI, Basel, Switzerland. This article is an open access article distributed under the terms and conditions of the Creative Commons Attribution (CC BY) license (http:/ / creativecommons.org/licenses/by/4.0/). 